\title{
Applying Business Process Change (BPC) to Implement Multi-agency Collaboration: The Case of the Greek Public Administration
}

\author{
Adamantia Pateli $^{1}$ and Sofia Philippidou ${ }^{2}$ \\ ${ }^{1}$ Ionian University, Department of Informatics, pateli@ionio.gr \\ ${ }^{2}$ Athens University of Economics \& Business, Department of Management Science and Technology, \\ sfilip@aueb.gr
}

Received 29 July 2010; received in revised form 11 November 2010; accepted 22 December 2010

\begin{abstract}
A great number of recent studies in the e-government area focus on investigating how technology-induced changes in the public sector connect with the New Public Management (NPM) reform, envisioned by many politicians. Researchers in this field contend that e-government denotes a structural and process-oriented change of governmental organizations, with the objective of getting them to run more efficiently. Adopting this perspective, this paper revisits a well-established business process change (BPC) methodology for the public sector and applies it to analyse the Greek initiative of Citizens Service Centers (CSCs) towards a one-stop hybrid (physical and electronic) government model. Considering the particularities of public organizations, we position our research as dealing fundamentally with ex-ante planned incremental changes at the micro level, being part of either a revolutionary or evolutionary transformation program at the macro level. We argue in favor of extending the six stages of the initially prescribed BPC methodology with an additional stage, named 'institutionalize change'. This serves the need of applying BPC to implement changes that enable multi-agency collaboration at a national level.
\end{abstract}

Keywords: E-government, Business process change, Integration, Multi-agency collaboration, Greece 


\section{Introduction}

The growth of the public sector in the 1970s and early 1980s has set the scene for subsequent pressures for reforms. Therefore, governments worldwide have engaged in ongoing high-profile and comprehensive reform plans. Implemented through a wide range of different change programmes, reform plans usually encompass a wide spectrum of changes, such as changes in the relationships between the central, regional and local level of administration as well as changes in the organizational design of public services [34].

From Sweden to Spain and from Portugal to Greece, reform policies have been put on the map in favor of new managerial practices in order to become more efficient and better respond to the needs of citizens ([48], [55]). Most reforms are oriented towards structural and process redesign of the public organizations with the aid of Information and Communication Technologies (ICTs). The use of information technology can provide powerful additions to the communication infrastructure of governmental agencies [22], generating significant information efficiencies and synergies [11]. Moreover, the use of telecommunications helps to promote the multiplicative gain that can be obtained through multi-agency collaboration.

The great majority of early e-government projects focused on redesigning a single governmental institution's services and information delivery, and thus generated internal efficiencies. Nevertheless, the latest developments in eGovernment at EU level have shown that there is value to be created through integration of services across the boundaries of departments and governmental agencies. These cross-governmental initiatives yield great promise for producing "better public services" and shift attention to processes, structures and information flows across the national governmental enterprise. Working at the national level allows sufficient scope and authority for redesign efforts [47].

Based on a progress study of the i2010 eGovernment Action Plan [13], an important issue of concern for the European Commission is the overall "flatlining" of citizen use of eGovernment services. More specifically, while almost all indicators of citizen online activity continue to show a year-on-year increase from 2004 to 2008 , the interaction with the public administration presents a downturn. An explanation provided concerns the need for a more deep-seated transformation in the way governments use ICT to provide services. A similar finding has been made by the OECD [40] which points to the need to shift the eGovernment focus from a government- and silo-centric to a user-centric approach. Many other commentators express the need for a transition from an eGovernment 1.0 government-centric phase, to a second-generation e-government 2.0 user-centric or user-driven phase before further significant take-up and impacts will be seen.

Within the last decade, several researchers have been interested in describing the evolution of e-government with the use of stage models ([5], [27], [30], [32]). Layne and Lee [32] have provided one of the most widely cited egovernment evolution models. This includes the following stages; (1) catalogue, (2) transaction, (3) vertical integration and (4) horizontal integration. Contrasting the previous model, Andersen and Henriksen [5] have developed a four-stage model (cultivation, extension, maturity and revolution) that shifts focus from what is technologically feasible to what is beneficial for the end-users, emphasizing the need for streamlining processes and improving communications with citizens. Taking a national perspective rather than that of single organizations, Klievink and Janssen [30] have proposed a five-stage model, defined based on two parameters; customerorientation and flexibility. This model consists of the following stages; (1) stovepipes, (2) integrated organizations, (3) nation-wide portal, (4) inter-organizational integration and (5) customer-driven, joined-up government.

Combining the i2010 Action Plan [13] imperative towards e-government 2.0 with the above research on stage models, one could argue over the requirement for more research regarding multi-agency integration and collaboration. Current research in this area could be primarily divided into studies investigating the interoperability issues raised (e.g. [9], [18]), and studies discussing the management and strategic aspect of this integration (e.g. [31], [36]). A middle level of integration, concerning processes and structures of public organizations that are transformed with the contribution of ICT technologies, is less commonly investigated.

This paper aims at closing this gap by applying a well-established business process change methodology, proposed by Kettinger et al. [28], in analyzing the implementation process of Citizens Service Centers, or KEP in their Greek abbreviation [43], a hybrid (physical and electronic) one-stop-government case. It contributes to existing BPR research by extending the traditional BPC methodology with the "Institutionalize Change" stage, which involves macro-level interventions concerning inter-department and inter-agency transactions. Moreover, it contributes to egovernment research by providing a change management approach for governmental organizations that wish to implement changes in a multi-agency collaboration level. Existing BPR approaches and tools that have been proposed for the public sector are limited and concern the individual level of governmental organizations.

This paper is structured as follows. The next section provides an introduction to the literature of business process change (methodologies, techniques, tools), as well as to the literature of change models, which is important in order to identify the particularities of e-government programs. Section 3 presents the research settings and methodology applied to achieve the primary research purpose of this paper. Section 4 applies the BPC methodology of Kettinger 
et al. [28] in analyzing the CSC implementation in the Greek public administration and argues in favor of its extension with a new stage. Section 5 discusses the main lessons learnt from the case study analysis, while the last section of this paper raises the main implications of this study for practitioners and researchers in the field.

\section{Business Process Change Literature}

The literature on business process change is rich and mostly dated within the 1990s decade. In their great majority, existing research studies concern the application of changes on business processes of the private sector. Within the last decade, the research interest on applying BPR in the public sector has increased. Moreover, several researchers are investigating the theoretical but also implementation links that seem to exist between BPR projects and the contemporary requirement for organizations to continuously change and innovate. Following, we present prime research conducted during the previous decade on frameworks/methodologies for redesigning business processes, more recent empirical research on applying BPR in the public sector as well as primary concepts of the organizational change literature.

\subsection{A Business Process Redesign Framework}

Business process change (BPC) has been defined as a strategy-driven organizational initiative to improve and (re)design business processes in order to achieve competitive advantage in performance through changes in the relationships among management, information technology, organizational structure, and people [21]. After that, it integrates a strategy-driven change effort and a method of process improvement with Information Technology (IT) introduction.

Business Process Reengineering (BPR) has arguably been the most popular and sweeping change management approach of the 1990s decade. The widespread attention, indeed hype, surrounding BPR can, at least partly, be attributed to the fact that BPR advocates an alternative perspective on how organizations should be studied and improved [25]. Business Process Reengineering (BPR) aims at improving the productivity of an organization by altering the organization's processes (intrafunctional, cross-functional, interorganizational). Information technology is seen as an enabler for reorganization [20].

In the literature, there has been some confusion regarding the use of terms like re-engineering, process change and redesign. Most BPR researchers use the term 're-engineering' to refer to radical changes and the term 'process change' or 'process improvement' to refer to incremental [61]. Both re-engineering and change are included in the definition of redesign.

Like most managerial innovations, BPR has passed from a long period of testing and experimentation with a wide range of methodologies, techniques and tools. A number of methodologies, techniques, and tools for BPR projects have been proposed by researchers and practitioners alike for modeling, analyzing and redesigning business processes. Several researchers in the BPR field have invested their efforts in reviewing and classifying such methodologies and techniques ([1], [2], [16], [19], [38], [61]). Nevertheless, using as criteria the scope of their analysis as well as the number of citations made so far, Kettinger et al.'s [28] study is discerned for providing an excellent summary and review of BPR instruments. Based on a literature review of BPR methodologies, techniques and tools, and interviews with 25 BPR consultants and vendors, Kettinger et al. [28] proposed a BPR Stage-Activity (S-A) Framework, including six stages, each of which was then subdivided into a number of activities, followed by their respective techniques and tools.

1. Envision: This stage typically involves the establishment of management commitment and vision, a review of business strategy and IT opportunities for improving the firm's overall performance. Some typical techniques and tools used in this stage include; Process/ CSF Matrix, Delphi Technique, IT/Process Analysis and Force Field Analysis.

2. Initiate: This stage encompasses the assignment of a reengineering project team, setting of performance goals, project planning, and stakeholder/employee notification and persuasion. Most commonly applied techniques and tools in this stage are; Project Scheduling and Quality Function Deployment.

3. Diagnose: This stage comprises classification of current practices and processes, in terms of activities taking place, resources used, communication exchanges, roles, IT infrastructure and costs. Characteristic techniques and tools in the diagnose stage comprise; Fishbone Diagram, IDEF0,3, Role Activity Diagrams and Hierarchical Colored Petri Nets.

4. Redesign: In the redesign stage, a new process design is developed, under the concern of meeting the strategic objectives set up at the envision stage and fitting with the existing human resource and IT architectures. If necessary, new structures and information systems are proposed. Typical techniques and tools used in this stage include; Force Field Analysis, IDEF0,3, Data Flow Diagrams, Role Activity Diagrams, and Simulation. 
5. Reconstruct: This stage applies change management techniques to ensure smooth migration to the new process model. During this stage, the necessary IT platforms and systems are implemented, and the users go through training and transition. In this stage, we come across the following techniques and tools; Force Field Analysis, Instruction-based Training and Socio-Technical System Design.

6. Evaluate: This last stage involves monitoring of the new process model to determine if it meets its goals and often involves linkage to a firm's total quality programs. Common techniques and tools in this last stage include; Activity-based Costing, Pareto Diagrams, Fishbone Analysis, Employee and Team Attitude Assessment and Total Quality Management (TQM) programs.

Later BPR research emphasized the limitations of existing methodologies in taking a holistic view of the organization ([54], [61]). Specifically, Valiris \& Glykas [61] identified the need for a methodology that views BPR from an organizational theoretic perspective. Their proposed methodology, called Agent Relationship Morphism Analysis (ARMA), included the following five stages: 1) Establishing the vision and objectives, the scope and mode of BPR, 2) Business modeling, 3) Business analysis, 4) Redesign, 5) Continuous improvement. Nevertheless, the stages of this methodology could fit the six stages of the S-A framework. Particularly, stages 1 corresponded to the 'Envision' and 'Initiate' stage, stage 2 and 3 discerned the activities involved in the 'Diagnose' stage into those concerning modeling and those concerning analysis of existing processes, stage 4 summarized the 'Redesign' and 'Reconstruct' stages, while stage 5 matched to the description of the 'Evaluate' stage. In the same vein, the five stages of the consolidated methodology proposed by Muthu et al. [37] could absolutely fit the S-A framework. After that, we consider the Kettinger et al. [28] framework as rather complete and, thus, appropriate for describing our BPR project for the public sector.

\subsection{Business Process Change and E-government}

While BPC has been widely investigated to analyze the impact of information systems introduction in the private sector, less research attention has been provided for applying this theoretical perspective in studying IT implementation in the public sector. Several researchers have identified a number of obstacles in applying BPC to the public sector ([4], [8], [52]). Besides cultural barriers, which are commonly stressed in literature, the difficulties in applying BPC to the public sector are founded in the nature of the political decision and production process [51]. Moreover, the democratic principles of legal equality, legal security and the rule of law impede the application of creative strategies in redesigning policy processes [56]. While an improved productivity may be the ultimate goal of $\mathrm{BPC}$ in the private sector, redesigning policy processes cannot aim solely to productivity.

The different principles of governance in the public sector make BPC projects for the public sector intrinsically more complex [52]. Due to the distribution of powers, such projects seemingly necessitate far higher degrees of consensus among salient stakeholders than is typical in the private sector. Scholl [52] identifies the imminent need for applying $\mathrm{BPC}$ as more vertical and horizontal integration occurs through e-government.

While several researchers have discussed the conceptual inter-connection of BPC and e-government, empirical research in this field is still in its infancy. In the recent literature, BPC has been applied to study a process change project at one of the Slovene ministries [53]. Nevertheless, the business process change project involved only one institution, which resulted in low potential for IT enablement and thus e-government implementation. Instead, in the case of BPC projects including inter-organizational processes, and thus more state institutions, the potential for IT enablement is quite high. After that, the need for, and subsequently the value of, applying BPC becomes even greater.

\subsection{Types of Change for the Public Sector}

The literature review on organizational change theories has shown that research in this field is complicated, as it is lacking common language and most of the times each scholar adapts his terminology for explaining change.

A great distinction in the change management literature is made between 'revolutionary' and 'evolutionary' types of change. Revolutionary change can comprise dramatic modification of mission, strategy and deep structure due to changes that have occurred by external and internal factors [15]. On the contrary, evolutionary change typically aims at improving activities within the organization in order to achieve higher levels of performance over time [7]. The fundamental factors distinguishing revolutionary from evolutionary change include the scale/magnitude and the pace of change. Revolutionary change is wide in scale, while the magnitude of evolutionary change is limited. Moreover, whereas evolutionary change occurs slowly and gradually, revolutionary change happens swiftly and in a multitude of organizational parameters simultaneously ([17], [60]).

Similarly to revolutionary change, 'radical' change is important in magnitude and happens suddenly [3]. Its distinguishing factor is that radical change is planned as a major change effort following analysis of whatever relevant new conditions have intervened in the life of the organization ([3], [23]). Thus, it is more inward looking, while revolutionary change is more externally driven from evolutionary forces [43]. Opposed to radical change, 'incremental' change is defined as ongoing, evolving and cumulative [62], concerning narrowly focused and bounded 
improvements of organizational parameters [60]. The pace of the change process comprises the fundamental distinguishing factor of radical versus incremental change [24].

Porras and Silver [49] provide another distinction of change; 'planned' versus 'emergent' change. Planned change is defined as deliberate, conscious and purposeful decision to improve the organization in some way or perhaps change the organization in a deeper, more fundamental way. Planned change has specific goals and it is manageable during its unfolding [45]. On the other hand, emergent change is described as the result of an ongoing adaptation of organizations in response to some unanticipated external change (e.g. the emergence of a new technology) [49].

The stable environment of public organizations necessitates the adoption of a planned incremental change with the purpose to reduce conflicting events that arise from the strong evidence of bureaucratic norms and rules [46]. A planned incremental change has the purpose to set new goals and actions aiming at moving the organization to a new equilibrium. Within public organizations, public managers set out to accomplish specific objectives and have clear vision of what kind of change they want to achieve, with the purpose to implement major reforms in the long run. Moreover, public organizations often come across evolutionary changes that may be part of other radical or revolutionary changes, as planned or emerging modifications at the micro level. For instance, wishing to transform to the New Public Management model, governments may set up a sequence of evolutionary change projects, including changes at internal business processes first, and then to external or inter-organizational processes, which inevitably result in structural changes [46]. Under this vein, the management literature has so far been preoccupied by the practice and outcomes of approaching public management to the managerial frameworks used in private organizations. The need for adopting more flexible, strategic and business oriented approaches to public organizations has led scholars to extract management practices from the business literature and try to apply them to public organizations. The 'New Public Management' (NPM) school of thought has broadly influenced public management reforms and introduced new managerial practices that put more emphasis on the market and on replacing the bureaucratic structures of public organizations with more flexible ones, as found in the private sector [50]. In general, this movement could be seen as a transformation from public bureaucracy to a model of more flexible administration [48] applying business process redesigns frameworks. New Public Management principles include redesign of key procedures for serving citizens, setting of quality standards for public services, efficiency improvements of human resources management procedures, and introducing a number of initiatives inspired by the business world ([44], [59]).

In this context, our research set out to address the challenge of applying a business process redesign framework in the case of Citizens Services Centers. We position our research as dealing fundamentally with an ex-ante planned incremental change at the micro level, being part of either a revolutionary or evolutionary change program at the macro level. We see some form of intentionality as a necessary but not sufficient condition for explaining the unfolding of the BPC project in the Greek government. Moreover, technology is seen as an enabler rather than cause of the transition from the traditional government model to the one-stop government model.

\section{Research Setting and Methodology}

For many years, the Greek public administration was functioning based on the bureaucratic model ([39], [57]), away from any business model. Slow integration of technology combined with non-adherence to EU regulations and lack of decision making at management level included the principal causes accounted for the inefficiency of the Greek public sector. These shortcomings in the operation of the Greek public sector had a strong negative impact on the interaction between the Greek state and citizens. Facing the citizen's displeasure towards public sector institutions, the Greek government had to set new standards for public services and include more business models into its operation. The objective was to improve the cost-benefit ratios and enhance public servants' skills to contribute to modernization of the administration. The key guiding vision behind the changes that were about to take shape was a strong orientation of the public services towards citizens [46].

The Citizen Service Centers (CSCs) constituted a change initiative of the Ministry of Internal, Public Administration and Decentralization (M.I.P.A.\&D.), aimed at importing a new model of transactions in the Greek public administration based on the NPM principles [42]. The main purpose of this initiative was the progressive simplification of administrative processes and their integration into a system of transactions, which was shared among multiple public administrations agencies. More specifically, the basic objective was to separate the "production" from the "services" in order to deliver more efficient information to citizens and, and thus be characterized as the cohesive ring between state and citizens. The CSCs were designed based on the "one-stopshop" philosophy. Compared to the previous situation, people no longer had to interact with dispersed administrations, both local and central with, sometimes, unclear boundaries of intervention and responsibility, to obtain information, authorisations or other services. In 2002, five pilot one-stop-offices were established - three in the Athens region, one in Crete and one more in Thessalonica. From the end of 2002 to 2005, almost a thousand CSC offices were established nationwide, with more than 870 transactional processes integrated in the system.

In this research, the choice of the CSC case was made on the basis that it constitutes an innovative change effort for the Greek government and a best practice e-government case for the European government. Evidence for that 
constitutes its participation in the 52 finalists selected for the European eGovernment Awards 2007 [12].

This research has employed a longitudinal exploratory study, taking place from 2001 till 2006, which provided data and insight on the technical, organizational, social, legal/regulatory and business challenges and complexities of this multi-year integration e-government project. In order to describe the CSC implementation, we employed three research methods: archival research, interviews and observation. Such triangulation reduces bias and is recommended in case study research [63]. First an archival search was conducted, such as mission statements, consultant's reports and official documents were analyzed. Second, individual interviews with executives of the M.I.P.A.\&D., being responsible for the implementation of CSCs, as well as technologists and public servants working in CSCs were accomplished. The total number of the interviews was 51 (31 provided by executive officers; 5 from technologists; and 15 from directors and employees in CSC) and the average time of each interview was about 4060 minutes in length. It was presumed that face-to-face interviews, rather than the use of structured questionnaires, would provide better understanding of this implementation effort. The interviews were semi-structured, which enabled us to better organize the natural flow of interviews. The interview questions focused on such issues as interviewees' perceptions about the CSC implementation process, the importance of e-government use and the necessity of introducing business process change methodologies in the Greek public sector.

According to the interview provided by the ex-Vice Minister of M.I.P.A\&D., "the main driving forces that led the Greek government to implement changes in the public administration included the technological innovation. The evolution of IT drove them to adopt more business oriented approaches and plan changes that should be effective, strategically oriented and efficient; in fact that would help to reduce cost". This can be seen as an institutional evolution and an evolution of management logics. The institutionalized change emphasizes the need of deep changes in the structure of public organizations in order to assure the full adoption of any technological project.

\section{A BPC Methodology Guiding Transition to E-government}

As mentioned above, this research employs a case study in order to analyse the way in which a Business Process Change methodology could be applied to describe the transition to a multi-agency collaboration model for the public sector. To this end, the Kettinger et al. [28] framework of IT-enabled change was adopted as a framework for the research. Nevertheless, their proposed BPC methodology focuses on establishing changes in micro-level organizational elements. BPC projects where more than one agency is involved may require for additional activities handling the multi-agency nature of such changes. To meet this requirement, an additional stage, addressing changes in the macro-level, is proposed in this paper. Macro-level changes are those that affect inter-agency and inter-branch relations [58]. The scope of such changes is so wide that interventions in the national legislation may be essential.

\subsection{Envision}

The financial instability of Greece in relation to other E.U. countries was obvious during the 1980s, and Greece was obliged to create new paths of reforms and implement them rapidly. The 1980s and 1990s were characterized not only by structural changes to reduce state control in Public administration and the labour market, but also by the intensification of the New Public Management (NPM) style reforms. In 1990s, the Greek government was enforced by the European Union to follow the E.U. directives for public sector modernization and change. They were afraid that; if the Greek public organizations never changed, they would eventually lose synchronization with their environment and with the rest European countries. The vice minister that was in power in that period generated the idea of providing more efficient services from a single point of interaction (one-stop-shop). In this stage, ideas were made explicit, named and incorporated into a cognitive map that related the new idea to existing conditions and to the external environment.

As soon as the ex-vice minister set the initial goals, the creation of a Steering Committee (SC), including a group of individuals coming from inside the ministry and from the broader governmental environment, took place. They had to understand and analyze the idea, but also propose specific actions for the implementation of the one-stop government initiative.

The SC members, being civil servants (middle management employees), were facing the challenge of implementing a new concept within the area of public administration. In the beginning, each individual (member) of the group conceived this new vision from a different perspective, because of their different educational and experience background. This diversity had as result the SC members to resist and even confront each other, thus causing the new vision not to be accepted in a broader consensus. The acceptance of the new vision by the SC members was a long process and the vice-minister maintained close contact with them in order to explain them the details of the realization of his vision. Therefore, much time was spent in building relationships and trust between the SC members and the vice-minister.

As soon as the implications of change were fully recognized among the SC members, the need for formal planning (planned change) and goal-setting emerged. Decisions on planned and coordinated actions for the implementation of 
the change effort were made. The SC defined a number of goals for the CSC implementation and operation. Operational goals were mainly set based on the opportunities that existed for changing the current process model.

Table 1 illustrates the results of an IT/Process Analysis, conducted under the purpose of identifying the key opportunities for redesigning key processes of the public administration with the aid of the available Information and Communication Technologies.

Table 1: IT/process analysis (envision stage)

\begin{tabular}{|l|l|l|}
\hline Process Type & Typical BPR Requirements & Capabilities of the Enabling ICT \\
\hline $\begin{array}{l}\text { Inter-organizational } \\
\text { Processes (e.g. change of } \\
\text { residence and registration in } \\
\text { the new municipal) }\end{array}$ & $\begin{array}{l}\text { Unify processes with overlapping } \\
\text { steps taking place in different } \\
\text { organizations. }\end{array}$ & $\begin{array}{l}\text { A national backbone network (SYZEUXIS) } \\
\text { connecting all institutions of the public } \\
\text { administration was under construction; } \\
\text { Inter-organizational Information Systems }\end{array}$ \\
\hline $\begin{array}{l}\text { Inter-functional Processes } \\
\text { (e.g. payment of municipal } \\
\text { taxes) }\end{array}$ & $\begin{array}{l}\text { Transfer information across } \\
\text { different departments of the same } \\
\text { institution. }\end{array}$ & $\begin{array}{l}\text { Enterprise Resource Planning (ERP) } \\
\text { systems; Local Networks (WANs, } \\
\text { Ethernet); Workflow \& Document } \\
\text { Management Systems; Data-warehouses }\end{array}$ \\
\hline $\begin{array}{l}\text { Interpersonal Processes } \\
\text { (e.g. electronic submission } \\
\text { of tax income statement) }\end{array}$ & $\begin{array}{l}\text { Remove intermediary and connect } \\
\text { two parties within a process. }\end{array}$ & $\begin{array}{l}\text { Web-based Applications; Portals; Self- } \\
\text { Service Kiosks }\end{array}$ \\
\hline $\begin{array}{l}\text { Informational Processes } \\
\text { (e.g. information for benefits } \\
\text { that are eligible for families } \\
\text { having many children) }\end{array}$ & $\begin{array}{l}\text { Disseminate vast amounts of } \\
\text { information and guide citizens to } \\
\text { the process steps. }\end{array}$ & $\begin{array}{l}\text { Web-based Applications; Portals; Self- } \\
\text { Service Kiosks }\end{array}$ \\
\hline
\end{tabular}

\subsection{Initiate}

In this stage, the SC decided the next steps, divided the work, set goals, figured out who else to involve and made public their commitments and timetable. The most important activities planned and executed were; a) selection of the external technology provider that should implement the technological infrastructure of the CSCs, b) simplification of certain processes, c) coordination of the municipalities, prefectures, and regions and d) management of the local agencies' communication with the ministries.

Additionally, specific actions and goals were set, so that implementation of the first five (5) pilot CSCs could begin. Sometimes, though, decisions and actions had to be taken in a group level between the SC and the technological provider. More specifically, the goal was to implement five (5) pilot CSCs, while the main actions to conduct included; finding the space to accommodate the first pilot CSCs in cooperation with the prefectures, municipalities and regions, defining the employment policies they had to follow in order to staff the CSCs, and achieving early adoption of the new software by the public servants.

\subsection{Diagnose}

The activities at this stage involved definition and classification of the principal causes for citizens' dissatisfaction from the Greek public administration services. Confronted with the inflexibility and inefficiency of the public sector, the Greek citizens had lost trust in it. Based on data provided through the archival research, the main problems faced by citizens in their everyday interactions with the state were the following:

- $\quad$ Lack of knowledge. Civil servants were not always aware of the precise number of documents and the exact process to follow that were required for the execution of a transaction, thereby causing confusion and unnecessary delays for the Greek citizens.

- $\quad$ Lack of the appropriate competencies and skills. Often, citizens had to confront the phenomenon of public servants' ignorance on who is responsible for what.

- Process Inconsistency. Similar departments of the Greek public institutions located in different regions of Greece, often differed in the number and type of documents required for the implementation of a specific process. 
- Lack of coordination. The lack of an appropriate mechanism for the coordination of activities among different public institutions wasted citizens' time and caused them to lose trust in the public sector.

- Lack of electronic communication. The Greek public government had lagged behind in the implementation of a backbone network connecting all public institutions.

Figure 1 illustrates a fishbone diagram designed at this stage to facilitate diagnosis of the main causes of the Greek citizens' dissatisfaction.

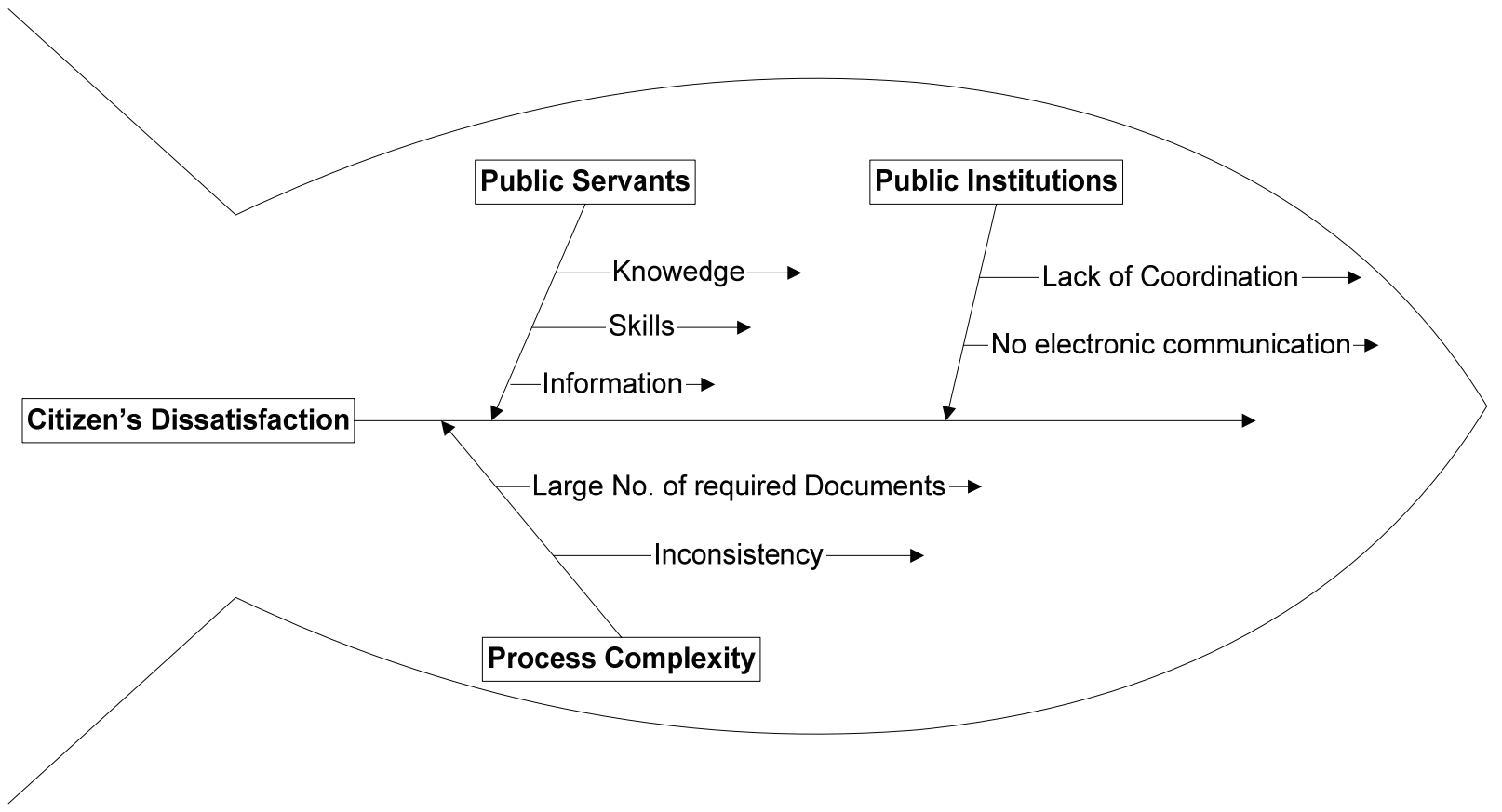

Figure 1: Fishbone diagram (diagnose stage)

\subsection{Redesign}

As mentioned above, the CSCs change initiative was organised by the Ministry of Internal, Public Administration and Decentralization (M.I.P.A.\&D.) in cooperation with all the municipalities, the regions and the prefectures of the country as well as with the associated technological providers. The structure was determined by the Greek Law 3013/2002. Each CSC followed a top-down structure, with an office manager at the top and several permanent and temporary employees in the back and front offices. The managers and directors of the CSC were permanent employees (public servants), authorised by the municipalities of the specific region to sign official documents and to make decisions on the daily operation of the CSCs.

Figure 2 illustrates the CSC operation as it was designed in order to serve citizens' requests. This includes the Redesign model proposed for the implementation of the one-stop government model in the Greek public administration.

\subsection{Reconstruct}

During the implementation of the five (5) pilot CSCs, the SC was relying on particular "sequenced steps" of implementation and was seeking to maintain consistency between action outlines in the plan with the actual progress of this change project. This meant that change started with a current time frame, then tackled the future and continued with linkages across time. The implementation progress was restrained by several difficulties, such as conflicts between the employees of the different entities.

Based on data of the archival research, the lack of efficient collaboration and communication between the pilot CSCs and the public administration (i.e. municipalities, ministries, prefectures) was the greatest problem that appeared in the change process. This was due to delay in introducing Information and Communication Technologies (ICT) in the public sector, and more specifically due to delay in the accomplishment of the SYZEUXIS project. The objective of this project was to develop and implement a broadband communication infrastructure enabling effective and speed connection of the Greek public administration to Internet. The absence of electronic communication, such as electronic mail, between the institutions, delayed the whole process as all the needed information was transferred by other means, such as courier, post mail and fax. Another problem that the pilot CSC faced concerned the operation of the "Thiseas" software to automate the CSC processes. Under these conditions, the SC carefully monitored 
difficulties in order to formulate the problems that appeared, to suggest corrective actions and to interact with the responsible players for providing solutions.

Figure 3 provides the results of a force field analysis conducted at the reconstruct stage of the CSC business process change program. The top part of the figure illustrates the main restraining forces that hindered the implementation of the CSC initiative. Instead, the bottom part of the figure illustrates the solutions that were worked out in order to drive the CSC initiative to success.

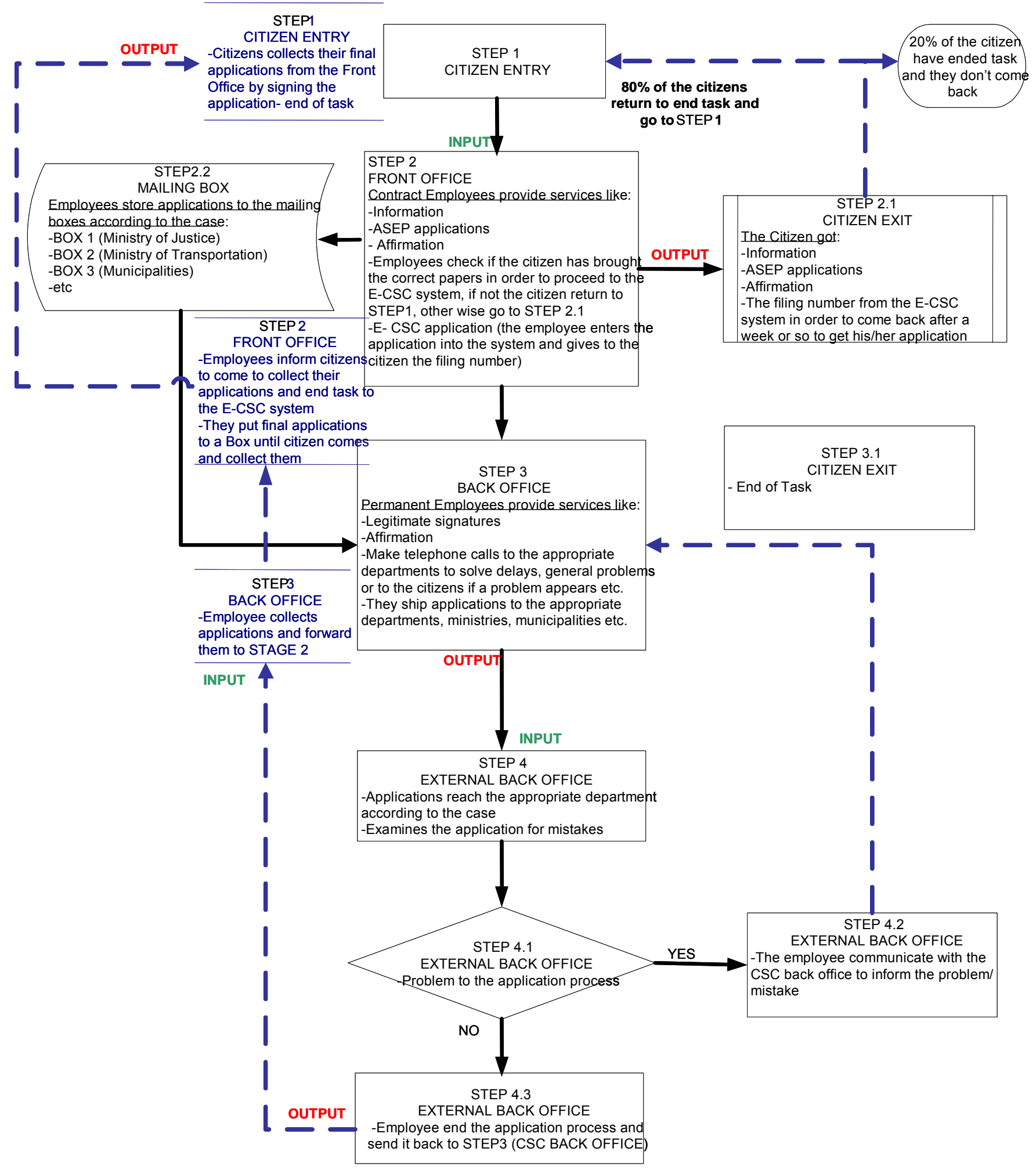

Figure 2: Flow chart (redesign stage) 


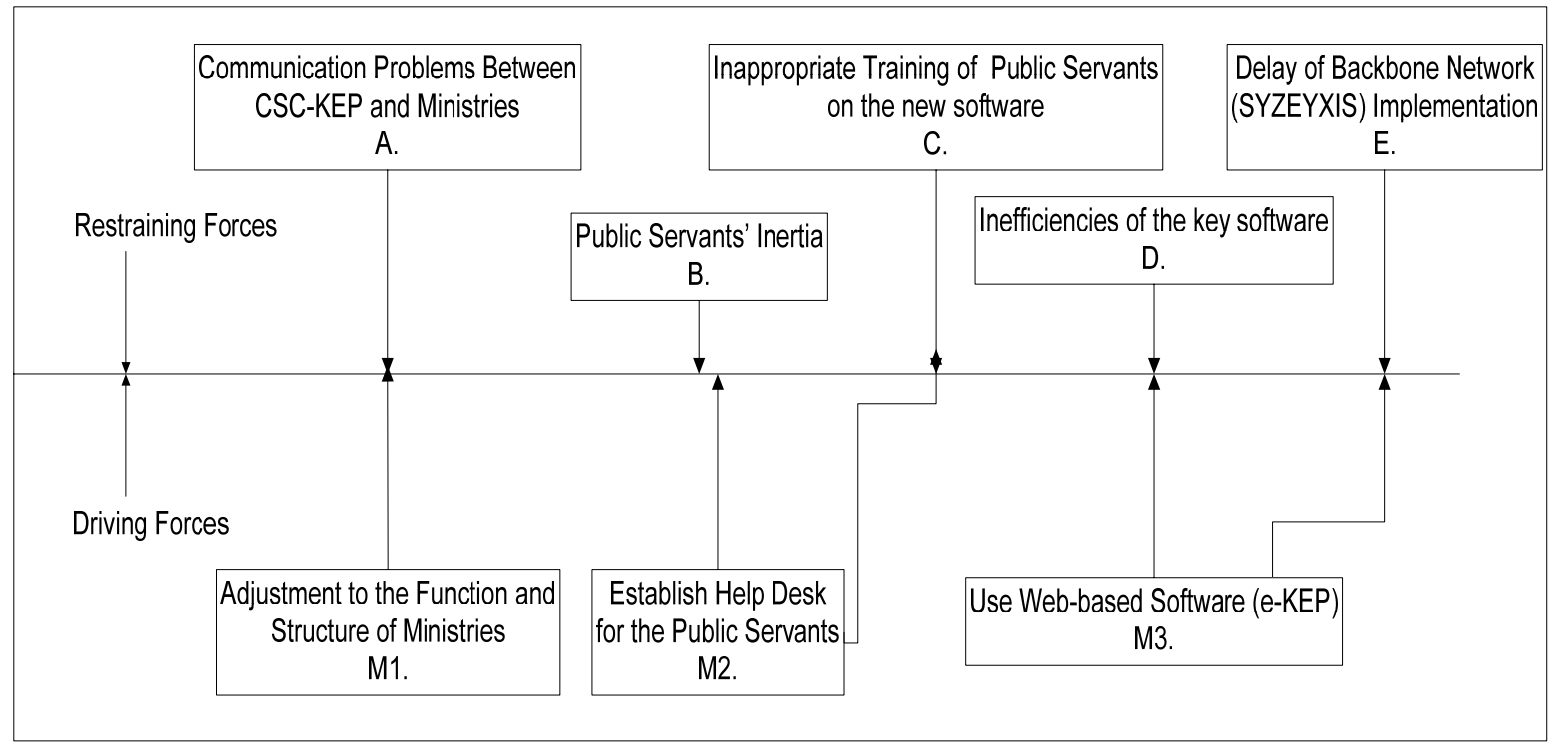

Figure 3: Force field analysis (reconstruct stage)

\subsection{Evaluate}

After the implementation of the five (5) pilot CSCs, an evaluation process concerning the CSC structure and operation began. This was a critical point in the change process, as the funding of the E.U. for the five pilot CSCs came to an end. Therefore, the SC had to critically evaluate the effectiveness of this initiative and decide its continuation, including modifications on its structural operation.

The evaluation process was based on statistical analysis data provided by the "Thiseas" software. Through the use of the "Thiseas" software, the SC had the opportunity to record; a) the number of transactions accomplished through the system, b) the number of citizens (in a daily rate) that successfully fulfilled their task, and c) the number of public institutions that provided resistance. The first results were very positive, as the follow-up mechanism showed that many processes were effectively executed through the CSCs and a large number of citizens used the facilities of the CSC offices. The positive reaction of citizens towards this effort encouraged the future plans of the SC and constituted a strong driving force for the expansion of this effort. It was the first time that citizens were positively positioned towards a technology-based innovation introduced by the Greek government. Undoubtedly, citizens had also some negative feelings towards the CSC operation, because it did not always respond to their requests. Considering all the negative aspects that appeared, the SC decided to move towards the expansion of this effort. Nevertheless, before proceeding to expansion, in order to limit the inefficiencies that appeared during the implementation of the first pilot CSCs, some modifications were made on the current CSCs' operation.

Figure 4 illustrates a fishbone diagram designed at this stage to assess the effectiveness of the CSC change effort taking into consideration four different perspectives; public servants, public institutions, citizens and processes. 


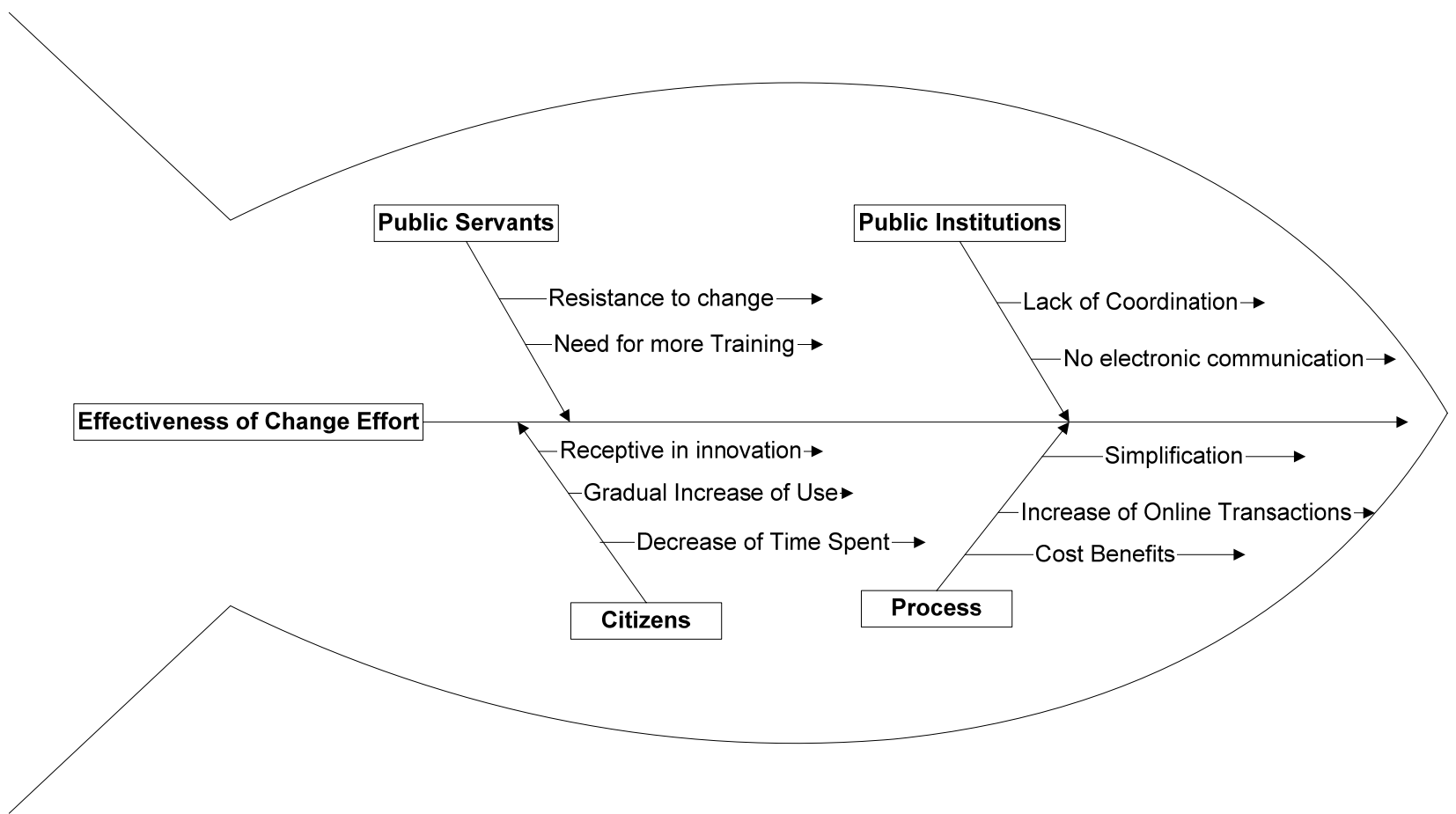

Figure 4: Fishbone diagram (evaluate stage)

\subsection{Institutionalize Change}

As soon as the evaluation process of the first pilot ones was over, and decisions on expansion were set, the SC decided to move towards the expansion of this change effort around Greece. Taking into account both the difficulties of the implementation of the five pilot CSCs and the positive and negative criticism provided by the Greek citizens, the public administration agencies and their employees, the SC proceeded to planning the CSC project's nationwide expansion.

In the "Institutionalize Change" stage, the Greek government decided to transfer the CSC's management under the financial coordination of the municipalities and prefectures, while the M.I.P.A.\&D. would hold the position of the coordinator. The principal modification of the CSCs' operation concerned the development of new employment policies, to which the Greek municipalities and prefectures had to comply. The new operational framework gave a "breath" to the financial difficulties of the M.I.P.A.\&D. to support this effort for any longer.

The decisions made at this stage triggered a new BPC effort, reengineering relations between multiple agencies of the Greek public sector. The existence of this additional step was justified by the need to assure continuance of the BPC programme implemented within the Greek public administration, leading to evolutionary transform of the Greek public sector.

A new stage of the BPC methodology is here in after proposed to assure successful implementation of this public change effort at the national level. This stage is defined to include modification of formal structures and HR management practices, diffusion of the innovation through trial runs and pilot projects, engagement of employees of all the involved governmental agencies in active participation tactics. Following the Kettinger et al. framework [28], we have identified a list of typical tools and techniques that could apply in this stage. These include Employee and Team Attitude Assessment, Job Design, Team-based Organizational Design, Simulation, Brainstorming, Visioning and Strategic Planning. Most of them are sourced from the Kettinger et al. [28] repository of BPC techniques and tools. The simulation technique has been previously proposed as a useful approach towards describing and understanding the dynamics of the collaboration involved in the case of information integration across governmental agencies [33]. Finally, the strategic planning technique is added in order to handle the requirement for planning incremental inter-agency changes in the public sector.

By including the "Institutionalize Change" stage within the BPC methodology, we wished to emphasize the need for changes in the wider scale, such as change of public organizations' structure or regulatory interventions, to assure full adoption and implementation of an inter-agency e-government project. Previous research in the public administration area has identified the importance of the activity "Institutionalize Change" by including it in the list of critical success factors of organizational change in the public sector [14]. Institutionalizing organizational change has emerged as an important issue among organization researchers and managers alike [29]. The literature argues that institutionalizing organizational change appears to be the best way to describe the relative perseverance of planned change efforts ([10], [26]). Perseverance means that the change effort has received sufficient acceptance by individuals and groups over a period of time to achieve the intended goals ([6], [35]) and in our case the introduction 
of a business change framework. However, of concern here is whether the desired change becomes part of the organization's ongoing activities to replace what existed beforehand.

\section{Lessons Learnt}

Facing the citizen's displeasure towards public sector institutions, the Greek government had to employ new managerial practices in order to provide more efficient services to citizens. More specifically, it had to set new standards for public services by improving the relationship between citizens and government, dealing with citizens in a helpful and courteous manner, reducing the time taken for fulfilling requests, simplifying procedures, and eliminating redundant formalities. The CSCs were designed based on the "one-stop-shop" philosophy with the purpose to deliver more efficient services to citizens from a single point of interaction. The main purpose of this reform was the progressive simplification of administrative processes and their integration into a system of transactions, which was shared among public administrations with as singular interface for the citizens the CSC Offices. From the citizen's point of view, the new system provided a significant advantage in terms of accessibility and reliability of public services. Compared to the previous situation, people no longer had to interact with several administrations, both local and central with sometimes unclear boundaries of intervention and responsibility, to obtain information, authorisations or other services. More specifically, the Greek Citizens Service Centers offered a wide variety of public services to citizens, resulting in streamlining more than 870 transactional processes.

The CSCs initiative was governed by the Ministry of Internal, Public Administration and Decentralization (M.I.P.A.\& D.) in cooperation with all the Municipalities, the Regions and the Prefectures of the country as well as with the technological companies responsible for the design, implementation, maintenance and development of the IT applications supporting the transaction processes. The involvement of many diverse agencies comprised an innovative feature of the Greek public sector, which resulted in conflicts between the different entities. In order to resolve them, the establishment of an experienced project team was required.

The M.I.P.A.\&D. was trying to import a new model of transactions in the public sector based on the NPM principles. More specifically, the basic objective of this effort was to separate the "production" from the "services" in order to deliver more efficient information to citizens. To achieve that, the M.I.P.A.\&D. required from the CSC's employees to have a more technology-based profile. Hence, there was a need for training existing employees that were moved from municipalities to CSCs but mainly recruiting new younger employees, who were more competent at using new technologies.

According to an executive officer of the M.I.P.A.\&D., after a theoretical review of different approaches of managerial practices and one-stop-offices concepts, they concluded that they should apply models and methods to the public sector inspired from the private sector. Also, the participation of executive officers in public administration seminars and conferences within the European Union widened their perspectives and provided important input in their search for applied models that would transform the Greek public administration successfully. The key guiding vision behind the changes that were about to take shape was a strong orientation of the public sector towards a process and structural reform that involved more than one governmental organization.

Our research aimed to describe the implementation of CSCs in the Greek public administration through the analysis of a business change management framework. CSCs constituted an innovative change effort for the Greek Public administration that tried to introduce new managerial and administrative practices, harmonized to the European Union directives along with private sector practices. The use of new technologies resulted in simplifying many processes for the advantage not only of the citizens but also towards minimization of the public sector's administrative costs. Taking advantage of ICT, many services were integrated while there were actions for decentralizing service delivery and monitoring.

The main changes that CSC change effort brought in the Greek public administration can be summarized as the following:

- Changes in the relationships between the central, regional and local level of administration,

- Changes in the organizational design of public services,

- Changes in the principles of financial management,

- Changes in the design of public policies,

- Changes in the evaluation of administrative outcomes and outputs,

- Changes in the relationship between state and society or between public services and citizens,

- Changes in internal but also inter-organizational processes of public administration bodies. 


\section{Conclusion and Further Research}

The present paper describes the application of a BPC methodology to describe an effort for reengineering information and service delivery processes in the public sector. Towards this aim, it employs a case study analysis on the Greek government's initiative for the implementation of one-stop offices serving citizens' requests from the public administration. Previous efforts in implementing BPC in the public sector have focused on redesigning processes of a single institution. In our case, BPC concerns changes of wider scale and scope. They are related to both processes and structure and target multiple agencies rather than a single organization. Particularly, the main challenges posed for the application of the BPC methodology in this case study included; a) implementation of planned and incremental changes regarding the citizen service process of the Greek public administration agencies, and $b$ ) requirement for transforming the inter-agency relations of the involved actors, by implementing macro-level structural changes (i.e. setting CSCs under the coordination and control of municipalities).

In its prescribed form, the BPC methodology applied in this research ends with an activity called "link to continuous improvement programs". Since this methodology was primarily designed to address changes in the private sector, this last activity concerns connection with the TQM programs planned by the management of firms. This paper raises the need for adding one more stage, named "Institutionalize Change", to link the BPC effort with changes implemented at the multi-agency collaboration level. Activities in this stage involve both managers of public organizations and civil servants. In most cases, governments' intervention is required to modify formal structures and procedures as well as human resource management practices. Such interventions may be accomplished through appropriate legal regulations. This stage also includes the activity of strategic planning by governments, which wish to adhere to external calls for transform (i.e. European guidelines). Hence, by introducing this new stage, we aimed at providing a BPC methodology that adapts to national but also European recommendations for organizational interoperability between multiple public agencies [41]. After that, the present paper contributes to existing BPR research by extending the traditional BPC methodology with the "Institutionalize Change" stage, which involves macro-level interventions concerning inter-department and inter-agency transactions, but also by demonstrating the applicability of business process management methodologies for the implementation of evolutionary change initiatives in the public sector.

Applying BPC in the public sector, and more specifically for implementing an e-government model, does not comprise a widely investigated area. The small number of relevant studies focuses on applying BPC for changing the internal processes of a single public organization ([8], [52-53]). Employing a case study analysis, the present paper comprises an attempt to provide evidence for the applicability of BPC in describing and monitoring changes at a wider, inter-organizational and national level. Hence, it contributes to e-government research by providing a business process management tool for governmental organizations that wish to implement changes in a multi-agency collaboration level.

In addition, the present paper raises a number of worth to be considered and investigated research questions, such as: a) Which are the critical success factors in conducting activities included in each stage of the proposed BPC methodology?, b) Is the BPC methodology appropriate for handling emergent or radical changes invoked in the public sector?, c) How the use of BPC can contribute to increasing European citizens' acceptance of online public administration services? Following, we provide several ideas for further investigating the above research questions. The analysis provided in this paper is based on a single case study. Hence, there is an opportunity for raising more knowledge from the examination of more relevant case studies, or even from their crossover analysis. Particularly, research based on multiple-case analysis would enable raising insight on critical success factors for each stage of BPC. Further research into other case studies would also assist in evaluating the extended BPC methodology and its efficiency in analyzing multi-agency collaboration projects.

In the present paper, BPC has been applied to analyze a change effort concerning evolutionary, incremental and planned changes. However, recent research is focused on identifying the relationship between e-government and New Public Management (NPM), involving radical and revolutionary changes of the public sector. Thus, it would be of high research interest to investigate the applicability of BPC in analyzing an e-government initiative involving emergent and radical changes (e.g. changes of the regulatory framework concerning the public sector) in the processes as well as in the structure of public organizations.

Last but not least, this research provides governmental people (managers, servants and committees), being responsible for the national e-government reforms, with a useful change management tool. This could be applied for managing the process of implementing planned and incremental changes on the service and information delivery processes of multiple agencies. In the present paper, we have chosen the Greek public administration case to employ the proposed BPC methodology. Since the citizen use of online public administration services presents a downturn at European level, the methodology could be provided as such for monitoring and guiding the change process for other European countries as well. 


\section{References}

[1] M. Al-Mashari and M. Zairi, Revisiting BPR: a holistic review of practice and development, Business Process Management, vol. 6, no. 1, pp. 10-42, 2000.

[2] J. Amis, T. Slack and C. R. Hinings, The pace, sequence and linearity of radical change, Academy of Management Journal, vol. 47, no. 1, pp 15-30, 2004.

[3] K. V. Andersen, Reengineering public sector organisations using information technology, in Reinventing Government in the Information Age - International Practice in IT-enabled public sector reform (R. Heeks, Ed.). New York: Routledge, 1999, pp. 312-330.

[4] K. V. Andersen and H. Z. Henriksen, E-government maturity models: Extension of the Layne and Lee model, Government Information Quarterly, vol. 23, pp. 236-248, 2006.

[5] R. S. Aguilar-Savén, Business Process Modelling: Review and Framework, International Journal of Production Economics, vol. 90, pp. 129-149, 2004.

[6] M. Beer, R. Eisenstat and B. Spector, Why change programs don't produce change, Harvard Business Review, Vol.6, no. 68, pp 158-166, 1990.

[7] W.W. Burke, Organizational Change: Theory and Practice. Thousand Oaks, CA: Sage, 2002.

[8] J. Burn and G. Robins, Moving towards e-government: a case study of organisational change processes, Logistics Information Management, vol. 16, no. 1, pp. 25-35, 2003.

[9] Y. Charalabidis and D. Askounis, Interoperability Registries in eGovernment: Developing a Semantically Rich Repository for Electronic Services and Documents of the New Public Administration, in Proceedings of the 41st Annual Hawaii International Conference on System Sciences, Hawaii, 2008, pp. 195.

[10] T. G. Cummings and C. G. Worley, Organization development and change. Cincinnati, OH: Southwestern., 1997.

[11] T. Dewett and G. R. Jones, The role of information technology in the organization: a review, model, and assessment, Journal of Management, vol. 27, no. 3, pp. 313-346, 2001.

[12] Epractice.eu. (2007) European eGovernment Awards 2007: Workshop for Finalists a Great Success. [Online]. Available: http://www.epractice.eu/files/download/awards/ExhibitionCatalogue2007.pdf.

[13] European Commission (2009, November) i2010 eGovernment Action Plan, Progress Study - Summary Report. [Online]. Available: http://ec.europa.eu/information society/activities/egovernment/studies/completed studies.

[14] S. Fernandez and H. G. Rainey, Managing Successful Organizational Change in the Public Sector, Public Administration Review, vol. 66, no. 2, pp. 168-176, March/April 2006.

[15] C. J. G. Gersick, Revolutionary Change Theories: A Multilevel Exploration of the Punctuated Equilibrium Paradigm, Academy of Management Review, vol. 16, no. 1, pp. 10-36, 1991.

[16] G. M. Giaglis, A Taxonomy of Business Process Modeling and Information Systems Modeling Techniques, The International Journal of Flexible Manufacturing Systems, vol. 13, pp. 209-228, 2001.

[17] R. Greenwood and C. R. Hinings, Understanding Radical Organizational Change: Bringing Together the Old and the New Institutionalism, Academy of Management Review, vol. 21, no. 4, pp. 1022-1054, 1996.

[18] L. Guijarro, Interoperability frameworks and enterprise architectures in e-government initiatives in Europe and the United States, Government Information Quarterly, vol. 24, pp. 89-100, 2007.

[19] A. Gunasekaran, B. Kobu, Modelling and analysis of business process reengineering, International Journal of Production Research, vol. 40, no. 11, pp. 2521-2546, 2002.

[20] M. Hammer and C. Champy, Reengineering the Corporation: A Manifesto for Business Revolution. New York: Harper Business, 1993.

[21] P. Harmon, Business Process Change: A manager's guide to improving, redesigning, and automating processes. San Francisco: Morgan Kaufmann Publishers, 2003.

[22] G. P. Huber, A theory of the effects of advanced information technologies on organizational design, intelligence, and decision making, Academy of Management Review, vol. 15, no. 1, pp. 47-71, 1990.

[23] Q. N. Huy, Emotional Balancing of Organizational Continuity and Radical Change: The Contribution of Middle Managers, Administrative Science Quarterly, vol. 47, pp. 31-69, 2002.

[24] Q. N. Huy, Time, Temporal Capability and Planned Change, Academy of Management Review, vol. 26, no 4, pp 601-633, 2001.

[25] Z. Irani, V. Hlupic, and G. M. Giaglis, Guest Editorial: Business Process Reengineering: An Analysis Perspective, The International Journal of Flexible Manufacturing Systems, vol. 14, pp. 5-10, 2002.

[26] R. L. Jacobs and A. M. Osman Gani, Institutionalizing Organizational Change through Cascade Training, in Proceedings of AHRD International Conference. Honolulu, Hawaii, 2002.

[27] M. Janssen and A. F. van Veenstra, Stages of Growth in e-Government: An Architectural Approach, The Electronic Journal of e-Government, vol. 3, no. 4, pp. 193-200, 2005.

[28] W. J. Kettinger, J. T. C. Teng, and S. Guha, Business Process Change: A Study of Methodologies, Techniques, and Tools, MIS Quarterly, vol. 21, no. 1, pp. 55-80, 1997.

[29] A. T. Kearney, Enterprise transformation: Mastering the art and science of mastering Change. London: A. T Kearney Ltd., 1999.

[30] B. Klievink and M. Janssen, Stage models for creating joined-up government: From local to nation-wide integration, in Proceedings of the 9th Annual International Digital Government Research Conference, Partnerships for Public Innovation, DG.O 2008. Montreal, Canada, 2008, pp. 117-123.

[31] R. Klischewski, Information Integration or Process Integration? How to Achieve Interoperability in Administration, in Proceedings of the EGOV04. DEXA, Zaragoza, Spain, 2004, pp. 57-65.

[32] K. Layne and J. Lee, Developing fully functional E-government: A four stage model, Government Information Quarterly, vol. 18, pp. 122-136, 2001. 
[33] L. F. Luna-Reyes, D. F. Andersen, G. P. Richardson, T. A. Pardo, A. M. Cresswell, Emergence of the Governance Structure for Information Integration across Governmental Agencies: A System Dynamics Approach, in Proceedings of the 8th annual international conference on Digital government research: bridging disciplines \& domains. Philadelphia, Pennsylvania, 2007, pp. 47-56.

[34] N. Michalopoulos, Aspects of Citizen-Public Services Relationships: The Case of Greece, Chinese Public Administration Review, vol. 1, no. 2, pp. 177-184, 2002.

[35] P. H. Mirvis and D. N. Berg, Failures in organizational change. New York: John Wiley, 1977.

[36] M. J. Moon, The Evolution of E-Government among Municipalities: Rhetoric or Reality?, Public Administration Review, vol. 62, no. 4, pp. 424-433, 2002.

[37] S. Muthu, L. Whitman and S. H. Cheraghi, Business Process Reengineering: A Consolidated Methodology, in Proceedings of the $4^{\text {th }}$ Annual International Conference on Industrial Engineering Theory, Applications and Practice. San Antonio, Texas, USA, 1999.

[38] P. O'Neil and A. S. Sohal, Business Process Reengineering: A review of recent literature, Technovation, vol. 19, pp. 571-581, 1999.

[39] OECD, Regulatory Reform in Greece, OECD Reviews of Regulatory Reform, 2001.

[40] OECD, Rethinking e-Government Services: User-Centred Approaches, Paris, 2009.

[41] M. Pankowska, National frameworks' survey on standardization of e-Government documents and processes for interoperability, Journal of Theoretical and Applied Electronic Commerce Research, vol. 3, no. 3, pp. 64-82, 2008.

[42] A. Pateli and S. Philippidou, Public Management Change and One-Stop Government Experience from the Greek Citizen Service Center (CSC), in Proceedings of the 2nd International Conference on Methodologies, Technologies and Tools enabling e-Government. Corfu, Greece, 2008, pp. 91-102.

[43] S. Philippidou, Towards a Holistic Theoretical Framework for the Unfolding of Planned Change in the Greek Public Sector, PhD Dissertation, Department of Management Science and Technology, Athens University of Economics and Business, Athens, Greece, 2007.

[44] S. Philippidou, K. Soderquist, and G. Prastacos, Towards New Public Management in Greek Public Organizations: Leadership vs Management and the Path to Implementation, Public Organization Review, vol. 4, no. 4, pp 317-337, 2004.

[45] S. Philippidou, K. Soderquist, and G. Prastacos, Towards a Holistic Theoretical Framework for the Unfolding of Planned Change, in Proceedings of the Annual Academy of Management Conference. Hawaii, USA, 2005.

[46] S. Philippidou, M. Karageorgiou, C. Tarantilis, E. Soderquist, and G. Prastacos, Meeting the Challenge of Technology- Driven Change Within an Instituional Context: The Greek Case, Public Administration, vol. 86, no.2, pp. 429-442, 2008.

[47] Politech Institute (2008, February) Towards a Common eGovernment Research Agenda in Europe. [Online]. Available: http://www.egovernet.org/upload/ERPT\%20Vol\%205\%20eGOVERNET.pdf.

[48] C. Pollitt and G. Bouckaert, Public Management Reform: A Comparative Analysis (2nd Ed.). New York: Oxford University Press, 2004.

[49] J. I. Porras and R. C. Silver, Organizational development and transformation, Annual Review of Psychology, vol. 42, no. 1, pp. 51-79, 1991.

[50] Public Management Service (PUMA) of OECD, Knowledge Management: Learning-by-Comparing Experiences from Private Firms and Public Organisations, In Proceedings of High Level Forum, Copenhagen, 2001.

[51] K. Schedler and M. C. Scharf, Exploring The Interrelations Between Electronic Government And The New Public Management: A Managerial Framework for Electronic Government, in Proceedings of I3E Conference (ECommerce, E-Business, and E-Government), Boston, 2001, pp. 775-788.

[52] H. J. Scholl, E-Government-Induced Business Process Change (BPC): An Empirical Study of Current Practices, International Journal of Electronic Government Research, vol. 1, no. 2, pp. 27-49, 2005.

[53] M. I. Stemberger and J. Jaklic, Towards E-government by business process change - A methodology for public sector, International Journal of Information Management, vol. 27, pp. 221-232, 2007.

[54] M. Stoica, N. Chawat, and N. Shin, An Investigation of the Methodologies of Business Process Reengineering, vol. 2, no. 11, 2004.

[55] C. Talbot, UK public services and management: (1979-2000) evolution or revolution, The International Journal of Public Sector Management, vol. 14, no. 4, pp. 281-303, 2001.

[56] M. Thaens, V. Bekkers, H. P. M. van Duivenboden, Business Process Redesign and Public Administration: A Perfect Match?, in Beyond BPR in Public Administration: Institutional Transformation in an Information Age (J. A. Taylor, I. Snellen and A. Zuurmond, Eds.). Amsterdam: IOS Press, 1997, pp. 15-35.

[57] N. Themelis, Transformation of the Public Administration in Greece, Report prepared by the Ministry of Interior Public Administration \& Decentralization, Greece , 1998.

[58] J. R. Thompson and S. L. Fulla, Effecting Change in a Reform Context: The National Performance Review and the Contingencies of "Microlevel" Reform Implementation, Public Performance \& Management Review, vol. 25, no. 2, pp. 155-175, 2001.

[59] H. Tsoukas and D. Papoulias, Managing Third-order Change: the Case of the Public Power Corporation in Greece, Long Range Planning, vol. 38, no. 1, pp. 79-95, 2005.

[60] M. L. Tushman and P. Anderson, Managing Strategic Innovation and Change - A Collection of Readings. Oxford: Oxford University Press, 1997

[61] G. Valiris and M. Glykas, Critical review of existing methodologies - The need for a holistic approach, Business Process Management, vol. 5, no. 1, pp. 65-86, 1999 
[62] K. E. Weick and R. E. Quinn, Organizational Change and Development, Annual Review Psychology, vol. 50, pp. 361-386, February 1999.

[63] R. K. Yin, Case Study Research: Design and Methods. London: Sage Publications, 2003. 